\title{
Terra forming of social systems and human behavior: a new era for Al, human-robotic interactions (HRI), and multidisciplinary social science?
}

\begin{abstract}
This mini-script seeks to generate concerns around an emerging field of work related to space exploration and the rest of society generated by the idea of human colonies in extraterrestrial environments (space stations, moons, and planets). There exists abundant literature on terraforming from biogeochemical conditions, however, there is very limited research about human behavior, interactions, and specific studies of relationships with robots and artificial intelligence into the environments presented previously. For this reason, and with the intention of not replicating the same problems derived from our human condition (violence, extractivism, corruption, etc) preliminary ideas are exposed to think and contribute to the emerging field of cosmoeducation or exo-humanities and others "exo -disciplines" oriented to alternated social systems and human behavioral for a new era of exploration.
\end{abstract}

Keywords: AI ethics, human robot interactions (HRI), social terraforming, exohumanities, posthumanities
Volume 6 Issue 4 - 2020

\author{
Édgar Giovanni Rodríguez Cuberos \\ Facultad de Ciencias de la Educación, Fundación Universitaria \\ Juan de Castellanos, Colombia
}

Correspondence: Édgar Giovanni Rodríguez Cuberos, Facultad de Ciencias de la Educación, Humanidades y Artes, Fundación Universitaria Juan de Castellanos, Tunja -Colombia, Email rodriguez.edgar26@gmail.com

Received: August 20, 2020 | Published: December 17, 2020

\section{Introduction}

"When you eliminate the impossible, what remains, while improbable, must be the truth."

\section{Mr. Spock.}

NASA and other National Space Agencies in different developed countries (Europe, China, Russian, Arab Emirates), research institutes (Public and private), and initiatives such as: METI, SETI, VIRGIN GALACTIC or SPACE X, have been working on the projection of what necessarily emerges in terms of space exploration, ways of life, and new interactions for human beings. ${ }^{1}$ Furthermore, it is already known that classic reviews such as Douglas A. Vakoch in 2011 and $2014^{2,3}$ started the definition of the social sciences and humanities field of study applied to the context of space exploration: the "exo" humanities and social sciences (exopolitics, exosociology, exoeducation such as exobiology term).

For many years the main topic of this study has corresponded to science fiction literature, but in reality, these are the most overwhelming fields of the moment where they fit such relevant topics as posthumanities, ${ }^{4}$ artificial intelligence, robotics and the effects of this on human behavior, ${ }^{5-9}$ and civilization in general. ${ }^{4,7,10}$ It is therefore very important to recognize that given the existing space research projections and programs (such as the different initiatives of governments or the private sector as well) they will surely involve an accompaniment from the social sciences and the humanities to pose other challenges in relation to the future of progress technological and human existing possibilities. ${ }^{11-14}$

One of those human existing possibilities is known as terraforming, STRELKA institute gives the following example ${ }^{15}$ and a new terraforming concept :

"The term terraforming usually refers to transforming the ecosystems of other planets or moons to make them capable of supporting Earth-like life, however, the looming ecological consequences of human activities suggest that in the decades to come we might need to terraform our own planet if it is to remain a viable host for Earth-like life."

For others researchers terraforming in an ethical way might be:

"The intention of modifying the environmental conditions of the neighboring planets in such a way that human colonization would be possible. The synthesis of this antagonism is ecopoiesis, a concept related to the creation of new ecosystems in other planets. Since all the multicellular biodiversity requires oxygen to survive, only extremophile microorganisms could survive in other planets. So, it could be carried out a simulation of a meteorite by taking to other planets portions of the terrestrial permafrost, or ocean or soil, so that if a single species could grow, a new ecosystem would start, as well as a new Natural History. As a conclusion, ecopoiesis should be the bioethical principle to guide practices and research in Astrobiology."

Nowadays, the ecopoiesis concept of Palhares \& Almeida dos Santos ${ }^{12}$ shows that: "the idea of ecopoiesis can also guide a future expedition to other planets: one line of research can be the complex task of identifying, isolating, cultivating and preserving 'the' microbe candidate to colonize another planet."

Undoubtedly the concepts given above are surely connected with the new impulse of renewing of space races and the two missions that have been sent to Mars (Figure 1 Tianwen-1; Perseverance), which clearly evidence the interest of different nations to begin a stage of conquest and spatial colonization (When Mars are a principal objective). However, this independent work reflects, on the one hand, the continuity of another style of the cold war and of low-intensity conflicts over the predominance of space administration and this use (not ecopoiesis perspective obviously or supporting like STRELKA), and on another hand, the visible problematic of an interesting field of a new type of focus in Social Science and humanities research in order to work in those aspects. ${ }^{6,13}$ 

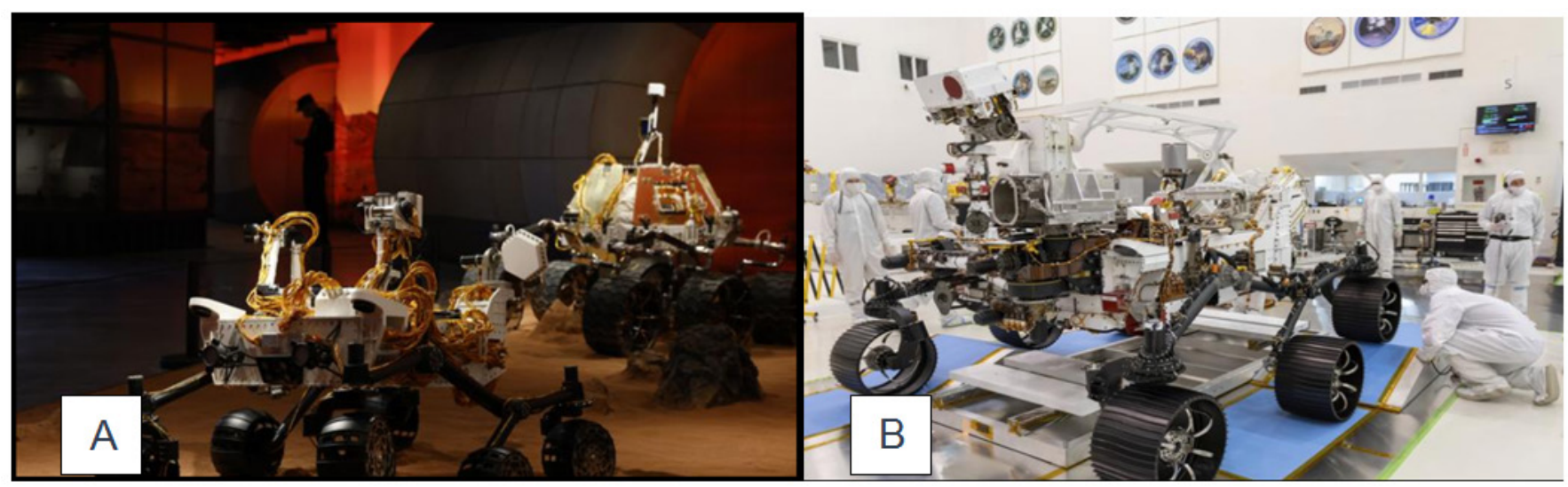

Figure I A. China Space Agency Rover vehicle. B. NASA Perseverance Rover vehicle. and emotional development. Both missions in addition to collecting samples and determining if microbial life existed at any time, they will collect data to establish the initial conditions for a future human mission. The initial stages consider the biogeochemical characteristics, but it is necessary to start working on the conditions that would maintain or generate new social relationships and their interactions with new factors such as $\mathrm{Al}$, robotics, and humans. In this case, the two rovers are a reflection of a rationality based on competitiveness and the idea of being the first colonizer of an unknown space and territory.

(Source:https://www.lavanguardia.com/ciencia/20200723/482473I20688/lanzamiento-mision-china-marte.html\#galeria-foto-2).

Perhaps in another historical moment, a rivalry between nations became a naturalized fact as part of a process in which a region and its "right" to exploitation was delimited. However, in the midst of the current pandemic, this persistence over a form of power dynamics and hegemony only replicates the model in which technological, scientific, and technical superiority prevails to guarantee rights over what is conquered (territory " wild and unexplored.”)

It is noteworthy that this event about exploration that is part of the current space race corresponds to a symptom of a type of rationality and understanding of scientific development and the idea of progress not only for sciences as well as humanity. Even and despite the efforts to have an international space station, we continue in a dynamic in which it is privileged to "arrive first", compete to be the best and who dominates the others in some way (the same occurs in the race for the vaccine of the COVID 19). This type of behavior that is structural to our way of understanding ourselves on the planet forces us to rethink our sciences as well, as they offer us different tools to think about the world and know it.

Many studies and researches have focused on other aspects related to behavior and especially previous studies in ethology, for example, the work of Eng, Douglas \& Verschure, 2005, in which the conditions of interaction in the use of space, displacement and their effects on behavior are worked from an interdisciplinary perspective to know the effects and how we generate certain responses within a model of sensors and effectors that are generated contextually, reactively, and adaptively which controls that influence learning and interactions with machines and artificial intelligence

(1):

"DAC consist of three tightly coupled layers of behavioral control: reactive, adaptive and contextual control. The reactive control layer provides a behaving system with aprewired repertoire of reflexes, which enable it to interact with its environment and accomplish simple automatic behaviors. The activation of any reflex, however, also provides cues for learning that are used by the adaptive control layer. Adaptive control provides the mechanisms for the adaptive classification of sensory events and the reshaping of responses supporting simple tasks"(2005:68).
This type of work not only demonstrates the need to expand studies on the behavior and human interactions of robots, machines, and artificial intelligence, but they also generate new contributions to the understanding of the ways in which we will have to adapt socially to these technological elements that act as supports or prostheses of our own behaviors.

In such a way that Terraforming, human multiplicity behaviors, and those new technological interactions will be much more complex than simply accepting their use without studying the impacts and consequences of isms in confinement environments. For this reason, the bio, psycho-social study that involves different variables, cultural, ethical, belief systems, chaotic and rational behaviors will determine the stability of space colonies in the short, medium and long term. In other words, I insist, it is about terraforming a new human rationality, recognizing our past to reinvent ways of life that are truly more coherent with our humanity.

Therefore, we can either observe or identify two clear trends in this type of research, those that consider the study of behavior from a positivist view of the sciences and those that involve more hermeneutic methods to account for the complexity of behavioral studies and its usefulness to know those new interactions, but above all, the tensions and forces that can only be considered in a transdisciplinary approach ${ }^{5-9}$ and much closer with the methods of the humanities and philosophy, ${ }^{4,7,10}$ In this train of thought, these prospective or "speculative sciences" 15 must enter the field of study with their statutes that confer objectivity, rigor, and systematicity in a way that complements other studies derived from the so-called applied sciences.

\section{Social systems "terraforming"}

Of course, the investigations carried out on adaptation processes currently include psychobiological aspects in which biometric variations and adjustment processes in terms of confinement and their effects are estimated. For NASA's Johnson Space Center (JSC):

"Scientists, physicians and engineers in the Space Life Sciences Directorate at focus on medical, health, biology, human performance and biotechnologyrelated aspects of human spaceflight. Their mission 
is to be the world's leader in understanding the space frontier and the opportunities, capabilities and limitations of humans living and working on that frontier".

Now, it is interesting and paradoxical that at this time and as a result of the global health crisis, the effects of confinement are taking place in our own spacecraft under the concept of GAIA Without a doubt, terraforming on other planets or bodies Celestial implies assuming the problems and situations that we have already been experiencing through quarantine and that accurately show the best and worst of our human behavior. Specifically, this is what we can and are able to avoid and that we must scientifically consider to enable a space exploration that takes care not to replicate the most unfavorable trends in our nature.

JSC says: "Scientists also investigate human behavior and performance in space, such as psychological adaptation to the confined and remote environment of a spacecraft. Insight into physiological effects provides scientists with a means to make crewmembers safer and more comfortable. Knowledge gained from spacebased research contributes to a deeper understanding of human physiology and psychology on Earth as well". ${ }^{11}$

This means that in addition to the traditional studies that are being carried out, a deeper perspective will be necessary for ethical terms and with a transdisciplinary approach, which are at least two important characteristics of these new exo-disciplines in the social and human sciences that here I try to promote and thereby develop a network and a new field of research with objects, theme, and methodologies that correspond to the complexity of this approach.

In such a way that Terraforming, behaviors and these new technological interactions will be much more complex than simply accepting their use without studying the impacts and consequences of isms in confinement environments. For this reason, the bio, psychosocial study, that involves different variables and interactions (Figure 2), cultural, ethical, belief systems, chaotic and rational behaviors will determine the stability of space colonies in the short, medium and long term. In other words, I insist, it is about terraforming a new human rationality, recognizing our past to reinvent ways of life that are truly more coherent with our humanity.

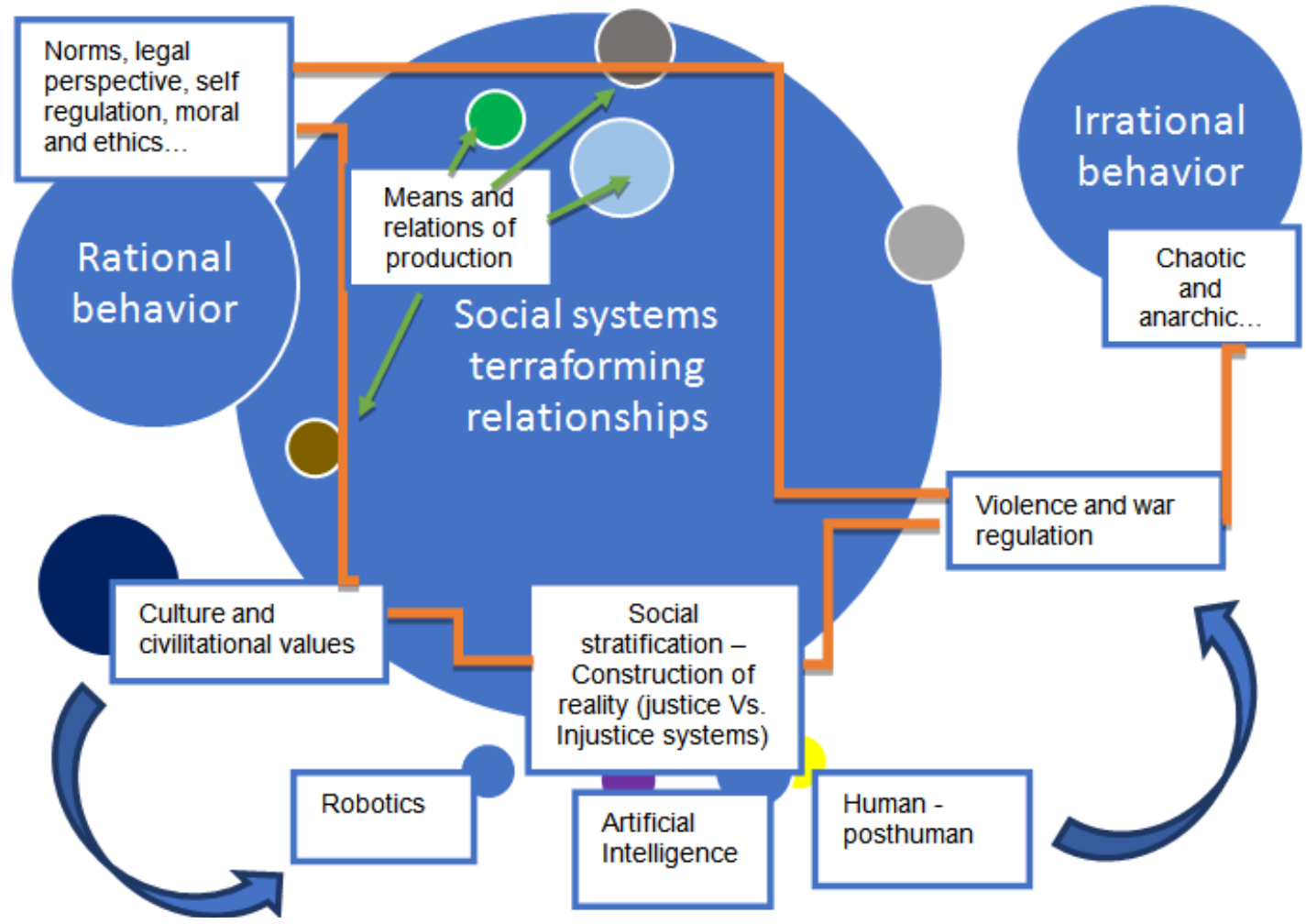

Figure 2 Proposed Model of Exo-social analysis: Social systems terraforming relationships depend on not only the recognition of our history as a civilization within a rational orientation but also interacts with an irrational vision in which a balance prevails in which the resolving forces are commanded by motivations typical of an advanced civilization. We must work on it and not simply repeat the models that we already know.

\section{A new social science?}

Surely I cannot affirm that it is a new social science, to the extent that the experiences of 2000 years of civilization are collected, in which the tendency has been to establish links according to similarities in our behaviors that has been more than demonstrated, for which, repetitively, we try to eliminate what we do not understand and that is different from us. The production base is focused on this model of domination and exploitation of other cultural forms as well as resources, however, in the face of these new possibilities that are generated, and that very possibly by 2050 , would allow us a human mission that remains a relative time on Mars, on the moon or in different space stations, we would have to ask ourselves about some important and paradoxical questions: What kind of conditions and principles of organization would we define to achieve the establishment of colonies on other planets or space bases? What types of factors would influence human interactions and behavior in relation to artificial intelligence, robotics, and the post-human condition? What social, political, economic, and cultural differences would emerge once human beings 
populate other places apart from the earth? Would this lead to new conflicts? How would new educational principles be defined for these new human communities and their off-earth born?

The previous and other questions should be the focus of these new nascent ex-disciplines, that is why, without a doubt, the categories of analysis and methods will have to be currently renewed to account for these other new realities and the accelerated evolution of a new type of humanity...In other words, the necessary emergence of a new paradigm for the sciences and particularly for the social sciences and humanities.

\section{Methodology}

In a preliminary review it is realized that when talking about terraforming, the preliminary interest has been about the biogeochemical conditions that would facilitate the establishment of human life either in space probes or directly in stations located on extraterrestrial surfaces. However, the topics of ethics and social and human studies in the field of Artificial Intelligence, robotics, and space exploration itself are quite rare. This is due to a prejudice that takes away from scientific consideration aspects that in philosophical or sociological terms ask about our behaviors in these new environments and not to repeat the bad practices that have led us to the environmental, economic, and social crises that have produced so many conflicts throughout history.

This initial work seeks to articulate with the METI initiative, ${ }^{14}$ recognizing in it the potential to be able to advance in transdisciplinary issues that can strengthen the ex-disciplines (Figure 3). For this, it is expected that this document will be perceived in the community of stakeholders at the planet level as a new platform for the exchange of ideas and the promotion of new theoretical innovations that collaborate with the development of the project of new social sciences and humanities-oriented towards space exploration and possible communication with other civilizations.

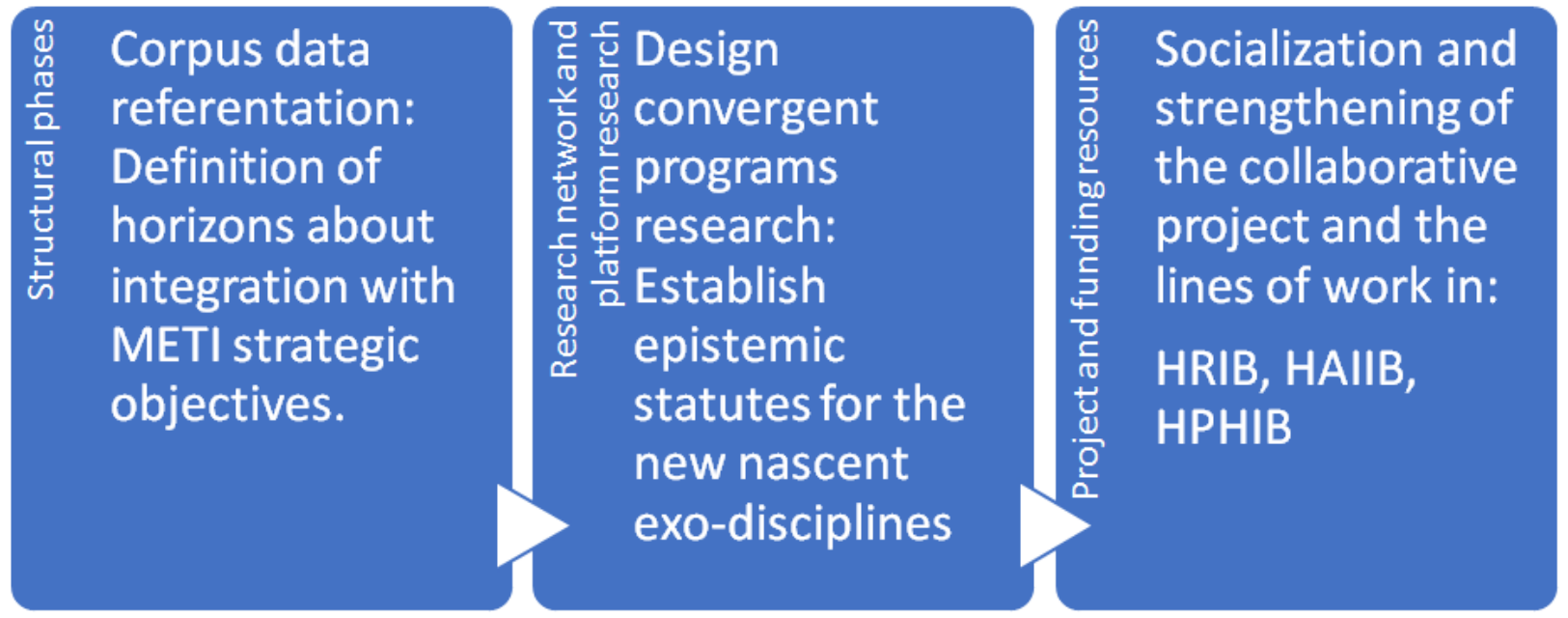

Figure 3 Initial work path for exo-social science and structural definition of exploration research in human-robot interactions and behavioral (HRIB); Human $\mathrm{Al}$ interactions and Behavioral (HAIIB) and Human Post Human interactions and Behavioral (HPHIB).

\section{Conclusion}

Since the beginning of the different space programs and missions, the problem of the behavior and response of human beings in extreme conditions of confinement or the exploration of new and unknown borders have been the subject of work: ${ }^{1}$

"Astronauts live and work in highly unusual and challenging environments where they must withstand multiple stressors. Their abilities to maintain positive psychological outlooks and good interpersonal relations are crucial for personal well-being admission success. From the inception of the space program, psychologists, psychiatrists, human factors experts, and other professionals have warned that the psychological stressors of space should be treated as a risk factor and that the risk would increase as missions involved larger, more diversified crews undertaking increasingly long flights". ${ }^{1}$

However, the volume of research and resulting proposals have only favored the basic aspects to guarantee the realization of those missions. A complexization of the space race and the consideration of longer times or of colonization implies the need for new parameters that not only improve the response to stress but also allow a coexistence dynamics consistent with these new situations.
In this order of ideas, this theoretical investigation pretends to be linked to one of the objectives established by METI ${ }^{14}$ in its development plan Objective 2.3: Foster Multigenerational Perspectives On Astrobiology That Emphasize Sustainability in which it manifests:

"The longevity of civilizations is intricately connected to questions of survival, especially in the face of increasing technological capabilities that may outstrip social development. One of the great challenges of surviving into the coming centuries is to cultivate sustainable environmental practices. But first, we must acknowledge the real threats that exist and the actions we can take in response. This requires changes in our actions and perhaps even our belief systems, as we shift from patterns of dominating nature to acting as stewards of the environment. Often it is not enough to have the scientific facts in front of us; recognition of both the need and the possibility of change can be fostered through literature, psychology, and philosophy. In the process of becoming a sustainable species, we may come to have a quite different understanding of what it means to be fully human".

It is very important that from this type of work and new studies, the proposed field of work can be strengthened given the need to rethink our practices as human societies and how we will very possibly assume our dynamics of interaction and behavior in new different 
environments of our planet. To do this, the first thing is to accept that these discussions are not a science fiction topic (although the utopian or dystopian debates and problems are generally born there) but a field proper to the humanities concerning social studies of robotics and artificial intelligence. As a Szocikc et al. ${ }^{9}$ conclude.

"We close our review of challenging and perhaps disquieting new technologies for human application by reminding the reader thatoffworld colonization may cause fundamental changes in human moral and ethical standards, especially when colonists are confronted with extraordinary dangers and challenges to human cooperation that they never envisioned. The biggest challenge for human cooperation on Mars will be permanent dependence on a life support system, dependence on delivery from Earth, and no possibility for evacuation or escape. Of the external physical stressors on the planet, we have highlighted the special dangers of radiation and lower gravity, but we also see the potential dangers of Martian rock dust to carry perhaps just as much danger for humans" (2020:12).

Therefore, Mars or Moon colonization may be asked about the implications of a space exploration that has been carried out by private companies and what are have been the types of interests that they mobilize, the complexities of human behavior in outer environments, the social dynamics that emerge from there and the ethical forms that it involves. An ontological position is defined so as not to risk a colonial, capitalist, and extractivist rationality that affects other extraterrestrial systems and generates the same environmental problems as on our planet.

Indeed, we can accept that terra forming processes are not only biogeochemical but also social, so that the study and research of typically human behaviors (violence, anguish, fear, joy, pleasure, etc.) will be in these new extraterrestrial environments subjected to another type of effects and causes. In addition to this, the interactions with the technologies of artificial intelligence and last generation robotics will generate a new type of situations that we have called exo-social sciences here and that mark a new work milestone for all human sciences. I would like to take the opportunity for this reflection to invite other researchers to configure this new field of study, which is the main objective of this writing.

Bearing in mind the previous issues if we could, as an academic and scientific community, overflow our limitations and egos derived from this modern rationality, new approaches would allow us to work and position these new exo-disciplines to address new issues and fields of work and thereby would contribute to a new consciousness of a real new era for IA, robotic humanities interactions, and social sciences.

\section{Acknowledgments}

To Prof. Nidia Marcela Cubides, @PhD.(Translate revision).

\section{Conflicts of interest}

The author declares there is no conflict of interest.

\section{References}

1. Harrison A, Fiedler, Edna. psychology and the U.S space program. in psychology of space exploration: contemporary research in historical perspective / edited by Douglas A. Vakoch. p. cm. -- (NASA history series) 2011.

2. Vakoch Douglas A. Ed. Archaeology, anthropology, and interstellar communication / 2011.p. cm. -- (The NASA history series).

3. Vakoch Douglas A. Ed. Psychology of space exploration: contemporary research in historical perspective / edited by Douglas A. Vakoch. 2014.

4. Rodríguez EG. La inmanencia de "Puppet Master": hacia unos estudios sociales poshumanos. Nómadas. 2017;47:123-135.

5. Eng Kynan, Douglas R, Verschure P. An interactive space that learns to influence human behavior. ieee transactions on systems, man, and cybernetics -part A: Systems and Humans. 2005;35(1).

6. Rodríguez EG. Las “otras” infancias que vienen: apuntes para una ética de la singularidad y subjetividad desde las interacciones niños-humanoides. Conference Congreso internacional presente y futuro de las humanidades. Universidad San Buenaventura., 27 al 30 de septiembre 2017.

7. Rodríguez EG. Learning interactions between robots and childs: new frontiers in future schools?.

8. Rodríguez EG. Ethical implications of emotional and psychologic ties on human robot interaction HRI mediated learning. International Robotics \& Automation Journal. 2019;5(5).

9. Szocika K, Wójtowiczb T, Boone R, et al. Ethical issues of human enhancements for space missions to mars and beyond futures. 2020;115:102489.

10. Rodríguez EG. Ciencia social performativa: alcances de una alternativa metodológica. Nómadas. 2008;29:142-155.

11. NASA. The human place in space. The science of living and working in space.

12. Palhares Dario. Almeida dos santos íris. astronomic bioethics: terraforming $\mathrm{x}$ planetary protection.

13. Qerimi Qerim R. Imagination, invention and internet: from aristotle to artificial intelligence and the 'post-human' development and ethics (June 12, 2020). The 21st century from the positions of modern science: intellectual, digital and innovative aspects (Elena G. Popkova \& Bruno S. Sergi, eds.), Springer, 2020:360-371.

14. METI. Messaging extraterrestrial intelligence. METI international's board of directors strategic plan, 2015-2018.

15. Strelka. The terraforming. 